\title{
Die evaluering van vyftien doringlose turksvykultivars (Opuntia ficus-indica (L.) Mill.) vir varsvrugteproduksie in die Pretoriagebied
}

\author{
A.B. Wessels* en L.C. Holtzhausen \\ Departement Plantproduksie: Afdeling Tuinboukunde, Universiteit van Pretoria, Pretoria 0002 \\ Ontung 12 September 1991; aanvaar 30 Oktober 1991
}

\section{UITTREKSEL}

Vyftien doringlose turksvykultivars (Opuntia ficus-indica) is vir drie agtereenvolgende seisoene by die Universiteit van Pretoria se proefplaas vir opbrengs geëvalueer. Eksterne en interne verwante vrugkwaliteitseienskappe is geidentifiseer en minimum standaarde is voorgestel. Vervolgens is die kultivars aan dié norme getoets en vergelyk. Die kultivars Morado, Algerian, Fusicaulis van Heerden, Fresno, Mexican en Nudosa het aan al die standaarde, of die meeste daarvan, voldoen. Die gevolgtrekking is gemaak dat dié kultivars die geskikste is om in die Pretoriagebied en streke met soortgelyke klimatologiese omstandighede vir varsvrugteproduksie aan te plant.

\section{ABSTRACT}

The evaluation of fifteen spineless prickly pear cultivars (Opuntia ficus-indica (L.) Mill.) for fresh fruit production in the Pretoria region

Fifteen spineless prickly pear cultivars (Opuntia ficus-indica) were evaluated for three successive seasons at the University of Pretoria Research Farm. Yields were recorded and external and internal fruit quality factors were identified and considered. Following this investigation, minimum standards were suggested and the cultivars under review were compared. The cultivars Morado, Algerian, Fusicaulis van Heerden, Fresno, Mexican and Nudosa met all or most of the standards set. It is concluded that for fresh fruit production these cultivars are best suited for planting in the Pretoria region and in areas with similar climatic conditions.

*Outeur aan wie korrespondensie gerig kan word. 


\section{INLEIDING}

Volgens De Kock ${ }^{8}$ is daar 35 benoemde kultivars van die doringlose turksvytipes in Suid-Afrika bekend. Dieoorsprong van die kultivars is die Burbank-kwekery in Amerika van waar 22 kultivars, as genetiese suiwer saad, gedurende 19l4 deur die Grootfontein Landboukollege te Middelburg, KP ingevoer en daar gevestig is. Sekere boere in die Karoo het ook van die oorspronklike materiaal op plase gevestig. Natuurlike kruisings het ontstaan en is as kultivars deur De Kock $^{7}$ geselekteer en benoem. Nie al die kultivars is geskik bevind vir varsvrugteproduksie nie, hoofsaaklik weens swak kwaliteit vrugte en/of lae opbrengspotensiaal. Sommige kultivars is by uitstek geskik vir veevoeding. ${ }^{\circ}$ Aangesien seleksie onder Karootoestande gedoen is, is daar gepostuleer dat dieselfde kultivars nie noodwendig soortgelyke gedragseienskappe in die Pretoria-omgewing, waar'n relatief' hoë reënval (gemiddeld $700 \mathrm{~mm}$ per jaar), matige somertemperature (gemiddelde maksimum $27,2{ }^{\circ} \mathrm{C}$ ) en matige wintertemperature (gemiddelde minimum $5,1^{\circ} \mathrm{C}$ ) voorkom, sal toon nie.

In hierdie ondersoek is 21 kultivars met die beste opbrengspotensiaal en vrugkwaliteit geselekteer en gedurende September 1981 op die Universiteit van Pretoria (UP) se proefplaas $\left[28^{\circ} 11^{\prime}\right.$ E.L. en $25^{\circ} 44^{\prime}$ S.B. $]$ gevestig. " Ses van dié kultivars in die proef is vir die doel van die ondersoek geskrap weens algemene swak prestasie.

Die opbrengs, vruggrootte (massa) en eksterne en interne $\mathrm{k}$ waliteit van die vrugte is oor'n tydperk van drie jaar in die eksperimentele boord bepaal met die doel om die geskikste kultivars vir die Pretoriagebied en gebiede met soortgelyke klimatologiese toestande te identifiseer vir aanbeveling om vir varsvrugteproduksie aan te plant.

\section{PROSEDURE}

Die volgende kultivars is gedurende September 1981 in 'n eksperimentele boord op die UP-proefplaas gevestig:
1. Fusicaulis
8. Hardy Bred*
15. Blue Motto*
2. Corfu
9. Muscatel
16. FusicaulisO.P.
3. Fresno
10. Fusicaulis van Heerden 17. Santa Rosa
4. Mexican
11. Oos-Kaap
12. Guayaquil
5. Morado
13. Skinners Court
18. Algerian
19. Niagara
20. Nudosa
6. Bakensk
7. Castillo
14. Direkteur*
21. Signal*

(* Kultivars nie gebruik in ondersoek nie weens algehele swak prestasie.)

Die proefuitleg bestaan uit 'n enkel ry van 10 bome per kultivar en is in 'n oos-wes-rigting georiënteer. Plantafstande is drie meter binne die rye en vier meter tussen rye. Die grondtipe is ' $n$ homogene, sanderige leemgrond met 'n noordwestelike helling.

Geen besproeiing is gedoen nie, en bemesting en ander boordpraktyke is op'n homogene basis toegepas. Dataneming is oor drie agtereenvolgende seisoene (1986, 1987 en 1988) op plantouderdomme vyf, ses en sewe jaar as volg gedoen:

1. Opbrengs: Die vrugte van elke plant is voor oes getel. Hierna is jaarliks 'n monster van 20 vrugte lukraak per kultivar verkry, individueel geweeg en die gemiddelde massa per vrug bepaal. Die gemiddelde opbrengs volgens getal vrugte en gemiddelde vrugmassa is na opbrengs per hektaar geprojekteer met die aanname dat daar 1000) plante per hektaar aangeplant is. (Die normale plantafstand vir aanplanting van turksvye is $2 \mathrm{~m} \times 5 \mathrm{~m}$.) As gevolg van voëlskade en moontlike diefstal van vrugte moes bogenoemde prosedure van opbrengsbepaling gevolg word ten einde akkurate data te verkry. Dieselfde vrugtemonsters is vervolgens gebruik vir eksterne en interne kwaliteitsbepalings.

2. Vrugmassa: Individucle vrugmassa is alangeteken.

3. Die blomentkelkdiepte van die vrug: Gemeet met 'n mikrometer vanaf die skouer van die vrug tot die diepste vlak van die krater.

4. Skilbaarheid van die vrug: Die konvensionele skilmetode vir turksvye is gebruik. 'n Arbitrêre waarde is toegeken volgens die gemak waarmee die skil van die vrugpulp geskei kon word.

Skaal:

$1=$ skil verwyder moeilik

$2=$ skil verwyder makliker

3 = skil verwyder baie maklik

5. Skildikte: Gemeet op twee lokaliteite op die ewenaar van die vrug $90^{\circ}$ uitmekaar. Die gemiddelde skildikte is vervolgens bereken.

6. Vrugpulpinhoud: Die skil van die vrug is verwyder en die pulpkomponent van elke vrug is individueel bepaal. Hierna is die persentasie pulp bereken. Die verhouding van pulp tot totale vrugmassa is bereken deur die massa van eersgenoemde deur vrugmassa te deel.

Hierna is die 20 geskilde vrugte per kultivar salamgevoeg en met behulp van 'n voedselverwerker versap. Die sade is deur sentrifugale aksie van die sap geskei.

Vervolgens is die volgende ontledings gedoen:

7. Saadinhoud: Die nat saadmassa is bepaal. Hierna is die saad gedroog en geweeg. 'n Lukraak monster van $2,0 \mathrm{~g}$ saad is verkry en die getal sade is bepaal. Die gemiddelde getal sade per vrug is bereken.

Aangesien die vrugmassa van die kultivars aanmerklik verskil het, is die getal sade. $100 \mathrm{~g}^{-1}$ pulp bereken sodat direkte vergelykings tussen kultivars getref kon word.

8. Saadgrootte: Tien sade is lukraak vanaf die $2,0 \mathrm{~g}$ monster verkry en die lengte (1), breedte (b) en deursnee (d) van die saad is gemeet. Die volume is as volg bereken: I $x$ b $x$ d = volume $\left(\mathrm{mm}^{3}\right)$

Weens die vorm van die saad is die volume slegs 'n arbitrêre waarde, maar relatiewe verskille tussen kultivars kon nogtans gedemonstreer word.

'n Variansie-analise is met behulp van "Statgraphics"program 2,6 op bogemelde resultate uitgevoer. Die KBV is bepaal by ' $n$ 95\%-peil van betekenisvolheid.

9. Inhoud van totale oplosbare vastestowwe (TOV): 'n Monster van die saamgevoegde sap is onttrek en die persentasie TOV is refraktometries virelke kultivar bepaal.

10. Titreerbare suurinhoud: Die suurbepaling is op sapmonsters gedoen deur titrasie met $\mathrm{NaOH}$-oplossing en phenolphthalien as indikator.'

\section{RESULTATE EN BESPREKING}

I. Opbrengs: Die gemiddelde opbrengs in terme van tonnemaat vrugte geproduseer.ha-1 .seisoen ${ }^{-1}$ word in tabel I aangetoon. Algerian en Santa Rosa het gemiddeld meer 
as 26,0 tha ${ }^{-1}$ opgelewer, gevolg deur Fusicaulis van Heerden met 17,6t.ha ${ }^{-1}$ en Mexican met 13,9t.ha ${ }^{-1}$. Fresno, Morado en Nudosa het jaarliks gemiddeld meer as 10 t. ha ${ }^{1}$ vrugte geproduseer.

Burbank ${ }^{4}$ meld 'n opbrengs van 100000$) \mathrm{lb}$. akker' ${ }^{-1}(112$ $430 \mathrm{~kg} \cdot \mathrm{ha}^{-}$) van sy verbeterde tipes. Die kultivar word egter nie genoem nie. Brutsch ${ }^{3}$ verwys na opbrengste wat wissel van 7,5 t.ha ${ }^{-1}$ tot 0,6 t.ha- I $\left(500\right.$ plante.ha ${ }^{-1}$ ) by Fort Hare Universiteit in die Ciskei. Sommige van die kultivars wat deur Brutsch ondersoek is, is ook in hierdie studie ingesluit.

Louw ${ }^{15}$ dui die opbrengs van alle doringlose turksvykultivars te Grootfontein Landboukollege in terme van gemiddelde getal vrugte per boom geproduseer aan, o.a. Algerian (674 vrugte.boom ${ }^{-1}$ ), Santa Rosa (284 vrugte.boom-1) en Corfu (339 vrugte.boom ${ }^{-1}$ ). Vergely-

TABEL 1

Gemiddelde vrugopbrengs (t.ha-1) van 15 doringlose turksvykultivars oor drie seisoene op die UP-proefplaas

\begin{tabular}{|l|c|c|}
\hline Kultivar & $\begin{array}{l}\text { Opbrengs } \\
\text { t.ha }{ }^{-1}\end{array}$ & Homogene groepe \\
\hline Corfu & 1,503 & $*$ \\
Guayaquil & 1,533 & $*$ \\
Fusicaulis & 1,687 & $*$ \\
Skinner Court & 2,875 & $* *$ \\
Oos-Kaap & 3,363 & $* *$ \\
Muscatel & 4,127 & $* *$ \\
Castillo & 5,340 & $* * *$ \\
Niagara & 6,523 & $* * * *$ \\
Nudosa & 10,187 & $* * * * *$ \\
Morado & 11,313 & $* * * *$ \\
Fresno & 13,577 & $* * *$ \\
Mexican & 13,873 & $* * *$ \\
Fusicaulis van Heerden & 17,567 & $* *$ \\
Santa Rosa & 26,143 & $*$ \\
Algerian & 26,283 & $*$ \\
\hline
\end{tabular}

$P=0.05$

TABEL 2

Gemiddelde vrugmassa $(\mathrm{g})$ van 15 doringlose turksvykultivars oor drie seisoene op die UP-proefplaas

\begin{tabular}{|l|c|c|}
\hline Kultivar & $\begin{array}{l}\text { Vrugmassa } \\
(\mathrm{g})\end{array}$ & Homogene groepe \\
\hline Fusicaulis & 86,89 & $*$ \\
Guayaquil & 88,22 & $*$ \\
Corfu & 92,32 & $*$ \\
Algerian & 103,17 & $*$ \\
Morado & 106,44 & $* *$ \\
Castillo & 109,16 & $* * *$ \\
Fusicaulis van Heerden & 113,20 & $* * *$ \\
Oos-Kaap & 117,98 & $* * *$ \\
Niagara & 121,80 & $*$ \\
Mexican & 123,78 & $*$ \\
Santa Rosa & 124,75 & $*$ \\
Muscatel & 132,47 & $*$ \\
Fresno & 138,54 & $*$ \\
Skinner Court & 141,56 & $*$ \\
Nudosa & 157,53 & $*$ \\
\hline
\end{tabular}

$P=0.05$ kende opbrengste vir dieselfde kultivars in hierdie studie is: Algerian 251.6, Santa Rosa 213,5 en Corfu 16,7.

Du Toit" verwys na 'n produksie van 10t.ha ' as ekonomies lewensvatbaar vir turksvye onder 'n droëlandboerderystelsel.

2. Vrugmassa: Tabel 2 dui die gemiddelde vrugmassa van kultivars oor drie seisoene aan. Nudosa produseer vrugte met die grootste gemiddelde massa (157,5 g), gevolg deur Skinners Court ( $141,6 \mathrm{~g}$ ) en Fresno (138,5 g). Fusicaulis $(87,0 \mathrm{~g})$ en Guayaquil $(88,2 \mathrm{~g})$ se gemiddelde vrugmassa is die kleinste.

Vrugmassa as sulks is nie 'n kwaliteitseienskap nie, maar lokale verbruikers gee voorkeur aan groter vrugte. ${ }^{12,13}$

Hoewel presiese inligting oor voorkeure met betrekking tot vruggrootte nie beskikbaar is nie, is die outeur van mening dat ' $\mathrm{n}$ minimum massa van $100 \mathrm{~g}$ as standaard gestel behoort te word. Brutsch ${ }^{3}$ stel egter 'n minimum massa van $80 \mathrm{~g}$ voor.

3. Blomentkelkdiepte van die vrug: In die literatuur word nie na hierdie eienskap wat hoofsaaklik kultivargebonde is as 'n kwaliteitseienskap verwys nie. Hoe dieper die blomentkelkkrater van die vrug, hoe minder ruimte is daar binne die skil vir pulpontwikkeling. Lakshminarayana, Sosa en Perez ${ }^{14}$ het die faktor ondersoek en gevind dat dit $26 \%$ van die totale lengte en $45 \%$ van die breedte van vrugte van $O$. anyclaea verteenwoordig.

Volgens resultate van hierdie studie (tabel 3) is die blomentkelkkrater van die vrug redelik kultivarspesifiek en wissel slegs marginaal van seisoen tot seisoen.

Volgens fenologiese studies vervlak die blomentkelkkrater progressief vanaf blomblaarval tot vrugrypheid. Groter vrugte en vrugte met 'n groter persentasie bevrugte of ontwikkelde sade het die neiging getoon om 'n vlakker blomentkelkkrater te produseer. ${ }^{19}$

In hierdie studie is gevind dat vrugte van Castillo (2,1 $\mathrm{mm}$ ) die vlakste blomentkelkkrater vorm, terwyl Moradovrugte $(7,2 \mathrm{~mm})$ die diepste krater het. Morado se pulpskil-verhouding is nietemin gunstig en die bevinding dui daarop dat 'n toleransie vir blomentkelkdiepte waarskynlik toegelaat moet word.

TABEL 3

Gemiddelde blomentkelkdiepte ( $\mathrm{mm}$ ) van 15 doringlose turksvykultivars oor drie seisoene op die UP-proefplaas

\begin{tabular}{|c|c|c|}
\hline Kultivar & $\begin{array}{l}\text { Bloment- } \\
\text { kelkdiepte } \\
(\mathrm{mm})\end{array}$ & Homogene groepe \\
\hline Castillo & 2,10 & * \\
\hline Guayaquil & 2,66 & $* *$ \\
\hline Corfu & 2,85 & $*$ \\
\hline Fusicaulis & 2,91 & $*$ \\
\hline Niagara & 4,69 & $*$ \\
\hline Oos-Kaap & 5.00 & $* *$ \\
\hline Mexican & 5,69 & $* *$ \\
\hline Fusicaulis van Heerden & 5,72 & $*$ \\
\hline Fresno & 5,73 & $* *$ \\
\hline Nudosa & 5,82 & $* *$ \\
\hline Skinner Court & 6,15 & $* * *$ \\
\hline Santa Rosa & 6,21 & $* * *$ \\
\hline Muscatel & 6,32 & $* *$ \\
\hline Algerian & 6,76 & $* *$ \\
\hline Morado & 7,24 & * \\
\hline
\end{tabular}

$\mathrm{P}=0,05$ 
4. Skilbaarheid van die vrug: Geen verwysing na die faktor kon in beskikbare literatuur opgespoor word nie. Gedurende hierdie studie is duidelike verskille waargeneem en daar is gepoog om aan die hand van 'n arbitrêre klassifikasie die skilbaarheid te kwantifiseer. Volgens tabel 4 skil Castillo (3) baie maklik, terwyl Nudosa $(1,05)$, Corfu $(1,53)$ en Guayaquil $(1,66)$ se skille moeilik verwyderbaar is. Hoewel die bevinding nie 'n direkte verband hou met vrugkwaliteit nie, benadeel dit die aanvaarbaarheid van die vrug vir die verbruiker. ${ }^{19}$

5. Skildikte en vrugpulpinhoud: Skildikte beinvloed die verhouding tussen pulpinhoud tot totale vrugmassa direk en daarom word die twee kwaliteitsfaktore gelyktydig aan die hand van tabel 5 bespreek. Met 'n ongunstige pulp-skil-verhouding ly die koper direk onder hoë vervoerkostes van die produk aangesien minder eetbare pulp vervoer en aangekoop word. Wanneer die skilkomponent baie klein is, impliseer dit 'n dun skil wat maklik beskadig word en waarskynlik meer gevoelig sal wees vir kneusing en na-oesbederf.

De Kock ${ }^{7}$ verwys na die skil-pulp-verhouding van dieselfde kultivars as wat in hierdie studie gebruik is. Wanneer resultate vergelyk word, blyk dit dat Santa Rosa, Algerian, Fusicaulis van Heerden en Mexican 'n gunstiger pulpskil-verhouding by die UP-proewe toon as te Grootfontein, Middelburg KP. Die ander kultivars het egter'n gunstiger pulp-skil-verhouding by laasgenoemde lokaliteit getoon. Lakshminarayana et $a .^{14}$ verwys na die pulp-skilverhouding van $O$. amyclaea-vrugte. Oor die algemeen is die verhouding by dié spesie gunstiger as by $O$. ficusindica.

Volgens resultate, soos aangetoon in tabel 5, is die pulpskil-verhouding van Mexican-, Santa Rosa-, Algerian- en Fresno-vrugte groter as 0,50. By Guayaquil- $(0,34)$, Corfu$(0,55)$ en Fusicaulis-vrugte $(0,38)$ verteenwoordig die pulp minder as $38 \%$ van die totale vrugmassa.

Organoleptiese en bemarkingstudies het getoon dat vrugte met 'n pulpinhoud van laer as $40 \%$ nie aanvaarbaar vir vars bemarking is nie. ${ }^{19}$

TABEL 4

Gemiddelde skilindeks van 15 doringlose turksvykultivars vir drie seisoene op die UPproefplaas

\begin{tabular}{|l|c|c|}
\hline Kultivar & Skilindeks & Homogene groepe \\
\hline Nudosa & 1,05 & $*$ \\
Corfu & 1,53 & $*$ \\
Guayaquil & 1,66 & $*$ \\
Fusicaulis & 1,70 & $*$ \\
Muscatel & 1,73 & $*$ \\
Niagara & 2,17 & $*$ \\
Mexican & 2,33 & $* *$ \\
Fresno & 2,40 & $* * *$ \\
Oos-Kaap & 2,40 & $* * *$ \\
Algerian & 2,49 & $* *$ \\
Santa Rosa & 2,50 & $* *$ \\
Morado & 2,55 & $* *$ \\
Fusicaulis van H eerden & 2,57 & $* *$ \\
Skinner Court & 2,80 & $*$ \\
Castillo & 3,00 & $*$ \\
\hline
\end{tabular}

$P=0,05$

Verklaring:

1 = skil moeilik, 2 = skil makliker, 3 = skil baie maklik
6. Saadinhoud en saadgrootte: Tabel 6 verstrek die gemiddelde saadinhoud. $100 \mathrm{~g}^{\text {' }}$ vrugpulp en die arbitrêre saadvolumes van kultivars wat in hierdie ondersoek gebruik is. Algerian ( 323 en $29,9 \mathrm{~mm}^{3}$ ), Morado (362 en $32,3 \mathrm{~mm}^{3}$ ), Niagara (383 en $26,3 \mathrm{~mm}^{3}$ ) het die laagste saadgetalle en kleinste sade respektiewelik. Die oorblywende kultivars het meer sade. $100 \mathrm{~g}^{-1}$ vrugpulp of die sade was groter.

Hoewel saadgetalle deur verskeie outeurs gemeld word, is dit nie op ' $n$ vergelykende basis in verband gebring met verskillende kultivars op 'n bepaalde pulpmassabasis nie. Standaarde ten opsigte van die kwaliteitsfaktore bestaan nie. Wessels ${ }^{19}$ stel op grond van bemarkings- en

TABEL 5

Gemiddelde verhouding van pulpmassa tot totale vrugmassa van 15 doringlose turksvykultivars oor drie seisoene op die UP-proefplaas

\begin{tabular}{|l|c|c|}
\hline Kultivar & $\begin{array}{l}\text { Verhouding } \\
\text { Pulpmassa } \\
\text { tot totale } \\
\text { vrugmassa }\end{array}$ & Homogene groepe \\
\hline Guayaquil & 0,335 & $*$ \\
Corfu & 0,349 & $* *$ \\
Fusicaulis & 0,376 & $* * *$ \\
Muscatel & 0,380 & $* * * *$ \\
Nudosa & 0,404 & $* * * * *$ \\
Morado & 0,427 & $* * * *$ \\
Oos-Kaap & 0,451 & $* * * *$ \\
Skinner Court & 0,469 & $* * *$ \\
Castillo & 0,477 & $* *$ \\
Niagara & 0,479 & $* *$ \\
Fusicaulis van Heerden & 0,495 & $* *$ \\
Fresno & 0,515 & $* *$ \\
Algerian & 0,528 & $* *$ \\
Santa Rosa & 0,531 & $*$ \\
Mexican & 0,582 & \\
\hline
\end{tabular}

$P=0,05$

TABEL 6

Gemiddelde saadgetalle. $100 \mathrm{~g}^{-1}$ vrugpulp en arbitrêre saadvolume $\left(\mathrm{mm}^{3}\right)$ vir drie seisoene op die UPproefplaas

\begin{tabular}{|l|c|c|c|}
\hline Kultivar & $\begin{array}{l}\text { Saad- } \\
\text { getalle } \\
\text { per 100 g } \\
\text { vrugpulp }\end{array}$ & $\begin{array}{l}\text { Saad- } \\
\text { volume } \\
\left(\mathrm{mm}^{3}\right)\end{array}$ & $\begin{array}{l}\text { Homogene } \\
\text { groepe } \\
\text { (saadvolume) }\end{array}$ \\
\hline Niagara & 838 & 26,295 & $*$ \\
Castillo & 328 & 29,010 & $* *$ \\
Fresno & 454 & 29,025 & $* *$ \\
Skinner Court & 304 & 29,710 & $* *$ \\
Algerian & 323 & 29,865 & $* *$ \\
Nudosa & - & 29,970 & $* *$ \\
Santa Rosa & 552 & 29,995 & $* *$ \\
Oos-Kaap & 415 & 31,720 & $*$ \\
Morado & 362 & 32,285 & $*$ \\
Fusicaulis van Heerden & 418 & 32,425 & $*$ \\
Mexican & 410 & 33,011 & $*$ \\
Muscatel & 249 & 33,480 & $*$ \\
Corfu & 488 & 43,820 & $*$ \\
Guayaquil & 380 & 44,025 & $*$ \\
Fusicaulis & 402 & 46,585 & $*$ \\
\hline
\end{tabular}

$P=0,05$ 
organoleptiese ondersoeke voor dat 400 ontwikkelde sade. $100 \mathrm{~g}^{-1}$ vrugpulp as maksimum toelaatbare getal vir bemarking van vars vrugte as norm gestel word, terwyl die maksimum arbitrêre volume van die saad nie $35 \mathrm{~mm}^{3}$ moet oorskry nie. 'n Toleransie word egter voorgestel vir 'n maksimum van 500 ontwikkelde sade. $100 \mathrm{~g}^{-1}$ vrugpulp indien die arbitrêre volume van die sade $30 \mathrm{~mm}^{3}$ of kleiner is.

7. Totale oplosbare vastestowwe: Afgesien van pulpinhoud is die TOV van turksvyvrugte waarskynlik die belangrikste kwaliteitsfaktor, aangesien dit die grootste bydrae tot die smaak van die vrug lewer. Tabel 7 toon die gemiddelde TOV-waardes oor drie seisoene vir die kultivars aan. Variasie in TOV is binne 'n kultivar vanaf een seisoen tot die volgende waargeneem. Sommige kultivars toon egter min variasie, bv. Fusicaulis, Fresno en Oos-Kaap. Die rede waarom TOV-inhoud varieer, kan moontlik toegeskryf word aan hoë reënval, beperkte sonskynure en lae grond $\mathrm{pH}$. Dieselfde kultivars in die Karoostreek produseer vrugte met TOV-waardes wat $2,0 \%$ en hoër is as in hierdie studie. ${ }^{2}$ 'n Moontlike verklaring vir dié verskynsel mag wees: laer reënval, meer sonskynure en alkaliese gronde.

Hare en Griffiths ${ }^{10}$ meld TOV-waardes vir $O$. ficus-indicavrugte wat wissel tussen $5,54 \%$ en $13,78 \%$. Die outeurs verwys nie na bepaalde kultivars nie. Sawaya, Khatchadourian, Saffi en Al-Muhammad ${ }^{18}$ meld 'n TOVwaarde van $14,5 \%$. Anon ${ }^{2}$ verwys na kultivars wat ook in hierdie studie gebruik is met ooreenstemmende TOVwaardes. Minimum standaarde vir die TOV-inhoud van turksvyvrugte is nie neergelê nie. Volgens Wessels ${ }^{21}$ behoort 'n minimum TOV-waarde van $12,0 \%$ te verseker dat die verbruiker 'n vrug koop wat aanvaarbaar vir vars gebruik sal wees.

TABEL 7

Gemiddelde TOV en titreerbare suurinhoud oor drie seisoene vir 15 doringlose turksvykultivars op die UP-proefplaas

\begin{tabular}{|l|c|c|}
\hline Kultivar & TOV & $\begin{array}{c}\text { \% Titreerbare } \\
\text { suurinhoud }\end{array}$ \\
\hline Morado & 14,4 & 0,08 \\
Oos-Kaap & 14,3 & 0,09 \\
Fusicaulis & 14,2 & 0,08 \\
Corfu & 14,1 & 0,12 \\
Fresno & 14,1 & 0,10 \\
Mexican & 14,1 & 0,10 \\
Castillo & 13,9 & 0,08 \\
Skinner Court & 13,7 & 0,11 \\
Niagara & 13,5 & 0,08 \\
Muscatel & 13,4 & 0,09 \\
Fusicaulis van Heerden & 13,4 & 0,11 \\
Guayaquil & 12,9 & 0,07 \\
Algerian & 12,2 & 0,08 \\
Nudosa & 12,2 & 0,07 \\
Santa Rosa & 12,1 & 0,08 \\
\hline
\end{tabular}

8. Titreerbare suurinhoud: Die suurinhoud van $O$. fic $u s-$ indic $t$-vrugte is uitsonderlik laag en wissel tussen $0,05 \%$ en $0,12 \%$ (tabel 7). Gemeet aan ander vrugtesoorte soos sitrus ${ }^{17}$ en pynappels ${ }^{16}$ word die afleiding gemaak dat die suurinhoud waarskynlik min bydra tot die smaak en kwaliteit van die vrug. Cantwell ${ }^{5}$ noem in dié verband dat die byvoeging van sitroensuur by $O$. ficus-indicavrugtesap die smaak merkbaar verbeter.

\section{GEVOLGTREKKING}

Voordat enige gevolgtrekking met betrekking tot kultivars gemaak kon word, was dit nodig dat faktore wat 'n rol speel by vrugkwaliteit geïdentifiseer word sodat bepaalde vergelykings tussen kultivars getref kon word. Die volgende eienskappe is geidentifiseer waarvoor daar ook minimum norme voorgestel is:

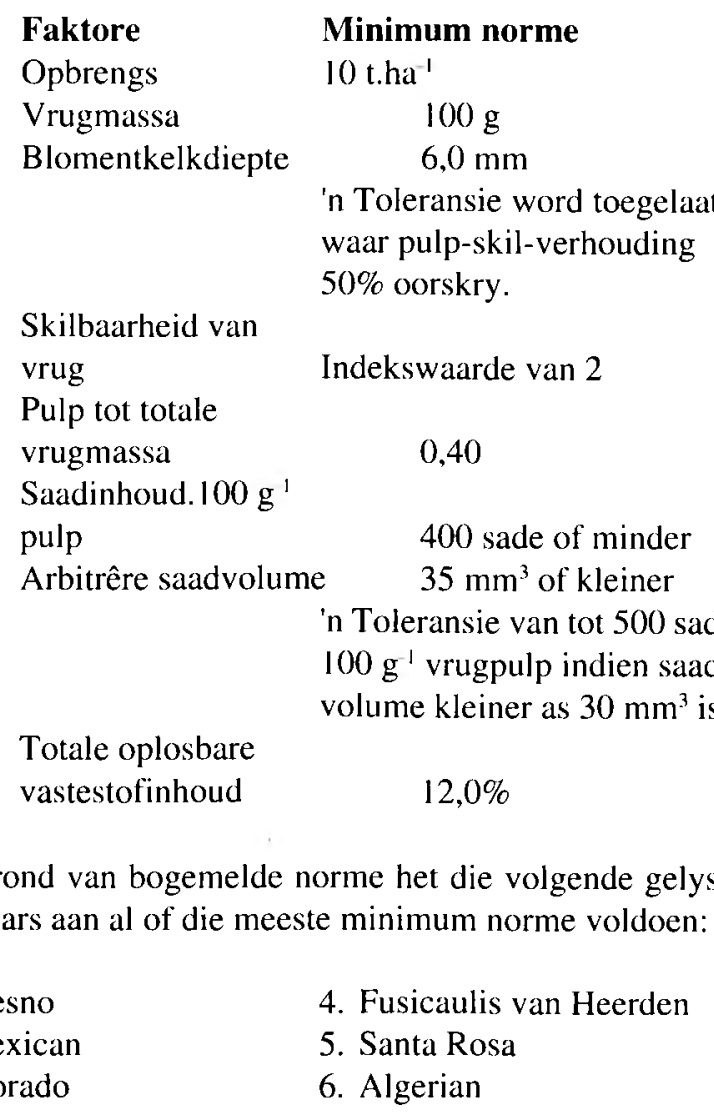

Dié kultivars word aanbeveel vir aanplanting in die Pretoriagebied en streke met soortgelyke klimatologiese toestande met varsvrugteproduksie as doelwit.

\section{LITERATUURVERWYSINGS}

1. Anon. (1983a). Staatskoerant van die RSA NO. 8617 (Maart 1983).

2. Anon. (1983b). Verwerking van subtropiese gewasse (xii) Turksvye, Nasionale Voedselnavorsingsinstituut, Afdeling Voedseltegnologie, Pretoria.

3. Brutsch, M.O. (1979). The prickly pear (Opuntia ficus-indica) as a potential fruit crop for the drier regions of the Ciskei, Crop. Prod., 8, 131-137.

4. Burbank, L. (1913). Luther Burbank's spineless Cactus (The Luther Burbank Co. San Francisco, California).

5. Cantwell, Marita (1986). Postharvest aspects of prickly pear fruit and vegetable cladodes. Co-operative Extention. Univ. of Calif. Perishable Handling, 59, June 1986, 6-9. 
6. De Kock, G.C. (1965). The management and urilization of spineless cactus (opumtia spp.), Sao Paulo, Brazil. Proc. IX Int. Grassland Soc., $1471-1474$.

7. De Kock, G.C. (1986). Persoonlike mededeling. (Dept. Landbou. Grootfontein Landboukollege, Middelburg).

8. De Kock, G.C. Ongedateer. Lys van beskikbare Joringlose turksvykultivars te Grootfontein Landboukollege, Dept. Landbou. Middelburg, KP.

9. Du Toit, D.C. (1988), Winsgewendheid van doringlose turksvyproduksie. Referaat gelewer hy Ist. Nas. Simposium Vrugteproduksie van doringlose nurksvye, Univ. van Pretoria. 2 - 4 Februarie 1988.

10. Griffiths, D. \& Hare. R.F. (1907). Summary of recent investigation of the value of Cacti as stock food. Government prining office, Washington. Bureau of Plant Industry Bull.. 102 (1), 5-16.

11. Holtzhausen, L.C. (1986). Persoonlike mededeling (Dept. Tuinboukunde, Univ. van Pretoria, Pretoria).
12. Howell, C.J. (1987). Persoonlike mededeling (East Lynn).

13. Howell. C.J. (1990). Persoonlike mededeling (East Lynn).

14. Lakshminarayana, S., Sosa. L.A.\& Perez, F.B. (1979). The development and postharvest physiology of the fruit of prickly pear (Opuntia amyclued Tenore), Trop. Foods, 1, 69-93.

15. Louw, Winnie (1989). Prickl' pear dom't abuse it, use it. (Commercial Printers, Porl Elizabeth).

16. Py, C., Lacoevilhe, J.J. \& Teisson, C. (1987). The pineapple: cultivation and uses (Maisonneuve et Larose Paris) p. 120.

17. Reuther, W.. Batchelor, L.D. \& Webber. H.J. (1986). The Citrus Industry, 2, 101. Div. of Agr. Sci. University of California.

18. Sawaya, W.N., Khatchadourian, H.A., Saffi, W.M. \& A I-Muhammad, H.M. (1983). Chemical characterization of prickly pear pulp, Opumia ficus-indica and the manufacturing of prickly pear jam, J. Fal. Techmol., $18,183-193$

19. Wessels, A.B. (1989). Morfogenese en potensiaal van die turksvyvrug Opuntia ficus-indica (L.) Mill.), D.Sc(Agric.)-proefskrif, Dept. Tuinboukunde, Univ. van Pretoria. 